\title{
The Rating System of the Rural School Pupils' Assessment of the Republic of Kazakhstan
}

\author{
Almurzayeva Bibigul $^{1, *}$, Shunkeyeva Orynkul ${ }^{1}$, Karavanova Lyudmila $^{2}$, Sagiyeva $_{\text {Aelita }}{ }^{3}$ \\ ${ }^{1}$ Institute of Education, Aktobe Regional State University named after K.Zhubanov, Kazakhstan \\ ${ }^{2}$ Faculty of Psychology and Social Work, Tver State University, Russia \\ ${ }^{3}$ Department of Foreign Languages, Aktobe Regional State University named after K.Zhubanov, Kazakhstan
}

Copyright $(\mathcal{C} 2015$ by authors, all rights reserved. Authors agree that this article remains permanently open access under the terms of the Creative Commons Attribution License 4.0 International License

\begin{abstract}
Currently, comprehensive school teachers of the Republic of Kazakhstan pay special attention to assessment system of pupils' knowledge based on personally oriented approach. In work "A black box: what there inside? An assessment of knowledge of pupils as a way of increase of efficiency of teaching and educational process" P. Blek and D. William note that "Improvement of quality of training at schools is one of important state priorities... initiatives for the purpose of improvement of planning and management, statement are more whole, more careful and frequent inspections - all this... doesn't give desirable feedback in improvement of teaching and educational process at school the conclusion arises: something in this scheme isn't enough... In our work we try to glance in a black box. We in detail consider such aspect of training as "the forming assessment" which is a basis of effective training" [1]. Today became quite obvious that in modern Kazakhstan education the traditional system of estimation of proficiency of pupils was insolvent. The assessment cult instead of a cult of knowledge dominates. Similar situation - result of the Former Soviet approach to system of estimation of pupils which assigned a duty to have an appreciation on all subjects to each pupil, and only three points from five are carried to that. In a 5-mark scale of estimation applied in Kazakhstan such points, as "2" and "1" - negative. The similar perception formally narrowed a 5-mark scale to the 3-mark. As a result teachers of schools are compelled by points "3", "4", "5" and the estimated judgments corresponding to them to estimate pupils of different level and different degree of readiness. This system of estimation operates on pupils of both comprehensive schools, and gymnasiums, lyceums, establishments of the correctional developing type. To distinguish these marks which are put down in documents on education as practice shows, it is simply impossible that is a serious contradiction. As a result we receive unauthenticated of an assessment of quality of training in general. Kazakhstan signed in 1999 the Bologna convention, is on the threshold of new educational reform - transition to 12 years' education. For this period
\end{abstract}

different systems of estimation were considered: 10-mark [2], 12-mark [3], 100-mark [4], test and modular system [5] and others. In this article we present the results of the pilot study on assessment system of rural schools in the Republic of Kazakhstan, Aktobe region Kenkiyak village. Having chosen the theme of the experiment: "Control and evaluation activities in conditions of transition to 12-year education system" a working group of teachers-experimenters choses one of its directions for detailed study - the rating evaluation system. At present in all territories of Kazakhstan a five-point evaluation system has been introduced, which may not always estimate the each child's individual development trajectory. The new evaluation system is introduced in order to create optimal conditions for efficient tracking of individual pupils' achievements using a rating evaluation system. The object of research throughout the work is the learning process of Mathematics, Cognition of the world, Chemistry, Russian and Kazakh languages in forms 3-8.Total in the experiment 10 forms were involved. The experiment took place during three years from 2009 to 2012. Results of conducted research were those changes in the teaching process, which have caused qualitative characteristics such as increased digestible material and depth of its understanding, the activity of pupils at the lesson, their creative independence, change of self-criticism and self-evaluation, etc. Rating assessment system allows to create maximal comfort environment of learning and upbringing, allows to transfer learning activities of pupils in internal need. The particular importance is the educational aspect of the new evaluation system for the pupil - from the self-discipline and to focus on his own interests and needs.

Keywords Assessment System, Rural Schools, Teachers-experimenters, Rating System, Education

\section{Introduction}


Currently, comprehensive school teachers of the Republic of Kazakhstan pay special attention to assessment system of pupils' knowledge based on personally oriented approach. In this article we present the results of the pilot study on assessment system of rural schools in the Republic of Kazakhstan, Aktobe region Kenkiyak village. Having chosen the theme of the experiment: "Control and evaluation activities in conditions of transition to 12-year education system" a working group of teachers-experimenters choses one of its directions for detailed study - the rating evaluation system.

At present at all territory of Kazakhstan a five-point evaluation system is introduced, which may not always estimate the individual each child's development trajectory.

\section{The Purpose of the Present Study}

The new evaluation system is introduced in order to create optimal conditions for efficient tracking of individual pupils' achievements using a rating evaluation system.

- The research problems are:

- providing management of methodical and experimental work;

- informative-enlightening and methodological work on the theme of the experiment with the teachers, students and parents;

- diagnostics-corrective support of the experiment with attraction of the school psychologist;

- control and analytical support of the experiment.

\section{Methods and Samples}

Methodological basis of the research of the chosen problem is existing theories and concepts in the pedagogical and psychological science: general philosophical theory of knowledge, education and training, a concept of the personally oriented approach, works of scientists psychologists, philosophers, methodists.

Research methods:

- comparative historical analysis of literature;

- general theoretical and heuristic methods of research;

- pedagogical supervision;

- conversation;

- pedagogical council;

- study and analysis of product documentation activities;

- study of the advanced pedagogical experience.

\section{Design of Experiment}

Object of research throughout the work is the learning process of Mathematics, Cognition of the world, Chemistry, Russian and Kazakh languages in forms 3-8.Total in the experiment 10 forms were involved. The experiment took place during three years from 2009 to 2012 .

Estimation is a process of collecting and the analysis information from various sources for deep understanding of what pupils know and how they're able to use their knowledge [6].

In our investigation 12-mark system of estimation was taken; the system was developed by the Kazakhstan scholars Zh. U. Zheksenbayeva.

The main functions of knowledge assessment are controlling, training, diagnostic, and educative and other [7].

During the experiment the following types of assessment were determined:

1) thematic: each mark that a pupil receives must

- be the result of the development of his specific theme;

- be means of systematization and generalization of pupils' knowledge;

- encourage pupils to a deeper and more lasting learning of basic provisions of specific theme;

be compulsory and its results are recorded in the log.

2) final: the estimation is carried out at the end of a quarter or academic year.

The assessment instrument of educational achievements of pupils is the score evaluation system. This assessment system suggests:

- differentiation of levels of mastering knowledge, abilities and skills together with knowledge of ways of pupils' learning activities for tracking their results;

- development of criterion-oriented assessment scale;

- ensuring the objectivity of assessment;

- providing the opportunity for pupils' self-estimation of their achievements;

- ensuring of transparency in the score accumulation as the basis for the development of motivation; observance of procedures of assessment's publicity.

\section{Findings}

Rating scale of quality assessment is normalized to 12 marks per lesson (this is the maximum score a pupil can get for all the required tasks). Assessment for the lesson is exposed considering the arithmetic mean of marks on a rating scale.

Assessment criteria are based on the positive principle. In this case all marks of 12-point scale are transferable, which are given in accordance with the level of training achievements of each pupil. This allows the teacher to plan and correct timely work and teaching methods of the next academic material.

Taking into account regularities of the teaching process the training results are monitored and evaluated as individual academic achievements of pupils accordingly to the levels of learning activity: on the first level of activity - reproductive, on the second level - productive and on the third level creative. 
On the first level of learning activity - reproductive academic achievements of pupils on gaining knowledge and skills are estimated within a separate subject.

On the second level - productive - pupils' activity on development of subject-specific competences is estimated. They are expressed in the ability to integrate knowledge and teaching skills, obtained by studying the different subjects' for solving cross-cutting issues.

On the third level - creative - pupils' activity on development of key competencies is estimated. The key competences are pupils' ability to transfer knowledge and experience for solving various learning and life situations on basic moral norms.

Academic achievements of pupils on the first level of learning activity are estimated from 1 to 5 points, which corresponds to the evaluation of "3", on the second level from 6 to 9 points - "4", on the third level - from 10 to 12 points - "5".

Criteria (evaluation criterion) of a 12-point scale assessment and value judgment of each point are presented in the following table [8].

Criterion-oriented scale is an instrument for assessment of pupils' academic achievements, allowing determining whether learners have achieved the specified knowledge and skills in certain subjects.

Obligatory condition of assessment is outstripping self-esteem of pupils' results of activity, which consists of comparing of the predictive self-assessment of the work with the reflexive self-assessment of the performed work, the ability to check and monitor themselves, critically evaluate their training activities, identify mistakes and find ways of their removal, as well as in their participation by the definition of evaluation criteria.

The accumulation of points allows evaluation's individualization of educational achievements, independent choice by pupil of an individual trajectory of his development and his capabilities, desires and abilities, deepen and broaden the knowledge and skills that will be reflected in the amount of its accumulated points in a certain period of time. Teacher promotes the development of self-management skills by the pupil. Objective evaluation by a pupil of his learning activity (self-esteem) is possible by the understanding by him content of value judgments of points within each academic subject. As a result of the accumulation of points pupils themselves, their parents and teachers have the opportunity constantly to track dynamics of the development of each pupil individually, comparing his own achievements in each period (quarter, year, etc.). Publicity of estimation allows solving many problems of a psychological nature, such as the conflict between pupils and their parents, conflicts between pupils and teachers, the conflict between teachers and parents.

7 teachers and accordingly, 7 classes participated in this research in such subjects as Mathematics and Cognition of the world in the primary level, Mathematics, Russian, Kazakh language, Chemistry in the basic level of a comprehensive rural school. It should also be noted the fact that because of the small number of children in rural areas, classes have no full complete set and are ungraded. At the beginning of the experiment with the teaching staff activities of introductory and educational character were conducted, a survey on identifying of the level of readiness for the innovative activity was conducted. At parents meetings teachers told about the essence of the research, its main directions in the learning activity of their children. A research as an essay on the topic: "What gives me the school mark", "What does not evaluate school assessment?", "What I expect from the new assessment system?" and so on was performed among the pupils.

Table 1. Assessment and evaluative judgments and learning activities of pupils on a 12-point scale assessment

\begin{tabular}{|c|c|c|c|}
\hline Levels of learning activity & Characteristic of learning activity & Value judgment & Marks in points \\
\hline \multirow{3}{*}{ Minimal } & \multirow{3}{*}{$\begin{array}{l}\text { Achievements of pupils are evaluated as satisfactory if } \\
\text { the pupil performs the actions on reproducing of } \\
\text { knowledge and skills }\end{array}$} & Badly & 1 \\
\hline & & Very weakly & 2 \\
\hline & & Weakly & 3 \\
\hline \multirow{3}{*}{ Sufficient } & \multirow{3}{*}{$\begin{array}{l}\text { Achievements of pupils are evaluated as good, if the } \\
\text { pupil demonstrates an understanding, i.e. performs the } \\
\text { actions on the interpretation and transformation of } \\
\text { knowledge and skills }\end{array}$} & Lower satisfactory & 4 \\
\hline & & Satisfactorily & 5 \\
\hline & & Insufficiently well & 6 \\
\hline \multirow{3}{*}{ Heightened } & \multirow{3}{*}{$\begin{array}{l}\text { Achievements of pupils are evaluated as very good, if the } \\
\text { pupil demonstrates the ability to application the mastered } \\
\text { teaching material in the standard situation, i.e. performs } \\
\text { actions on integration of knowledge and skills }\end{array}$} & Better & 7 \\
\hline & & Well & 8 \\
\hline & & Very well & 9 \\
\hline \multirow[b]{2}{*}{ High } & \multirow{2}{*}{$\begin{array}{l}\text { Achievements of pupils are evaluated as excellent, if the } \\
\text { pupil demonstrates the ability to application the mastered } \\
\text { teaching material in nonstandard situation, i.e. performs } \\
\text { actions on transformation of knowledge and skills }\end{array}$} & Almost excellent & 10 \\
\hline & & Excellent & 11 \\
\hline
\end{tabular}


Analysis of the essays showed that the current evaluation system does not allow pupil to identify personal development path, there is no "right to fail", and sometimes decreases their self-esteem (Figures 1,2,3).

\section{What gives me the school assessment?}

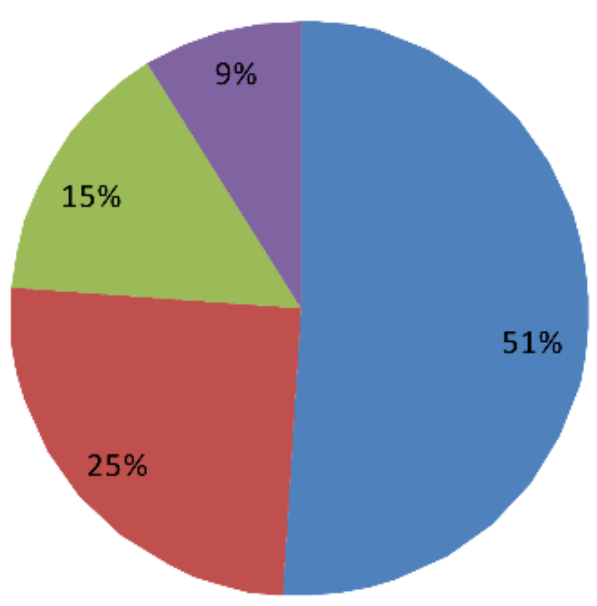

Determines the level of learning achievements (51\%)

Concretizes the corrective work on addressing gaps $(25,2 \%)$

Effects on the their self-esteem $(15 \%)$

sometimes random nature of evaluation $(8,8 \%)$

Figure 1. Results of school assessment by pupils

\section{What gives me the school assessment?}

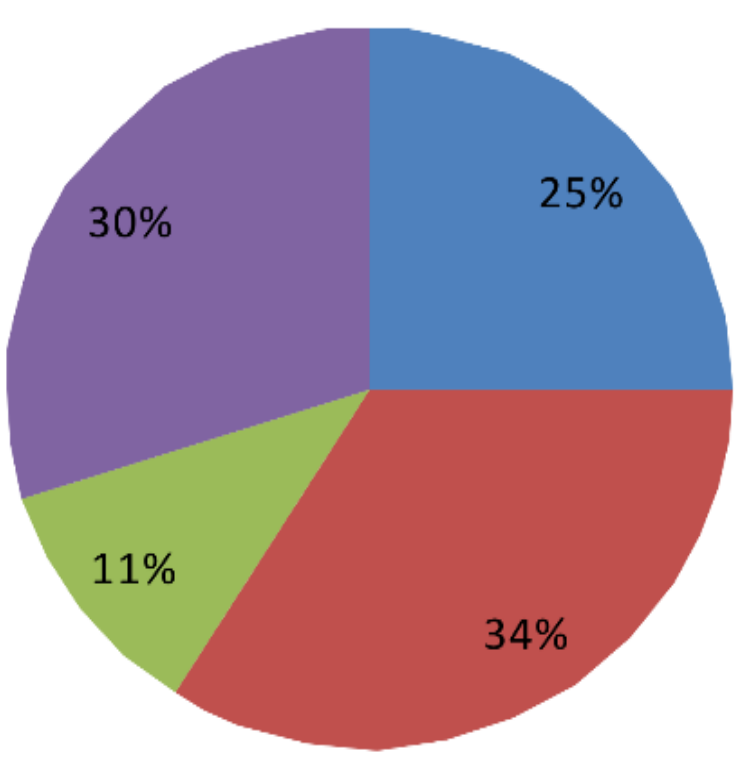

objectivity (25\%)

social security $(34 \%)$

changethe random character of evaluation (11\%)

motivation for learning (30\%)

Figure 2. Results of school assessment in terms of evaluation 


\section{What gives me the school assessment?}

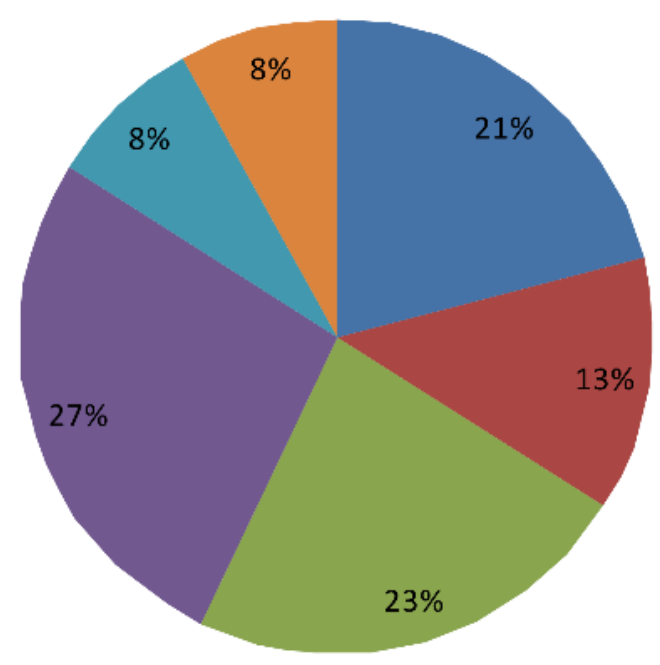

Increasing motivation to the teaching, self-activity (21\%)

Development of critical thinking $(13 \%)$

Formation of positive selfesteem (23\%)

Monitoring the growth dynamics of educational achievements (27\%)

Development of perseverance, dedication (8\%)

Figure 3. Results of new school assessment in terms of expectations

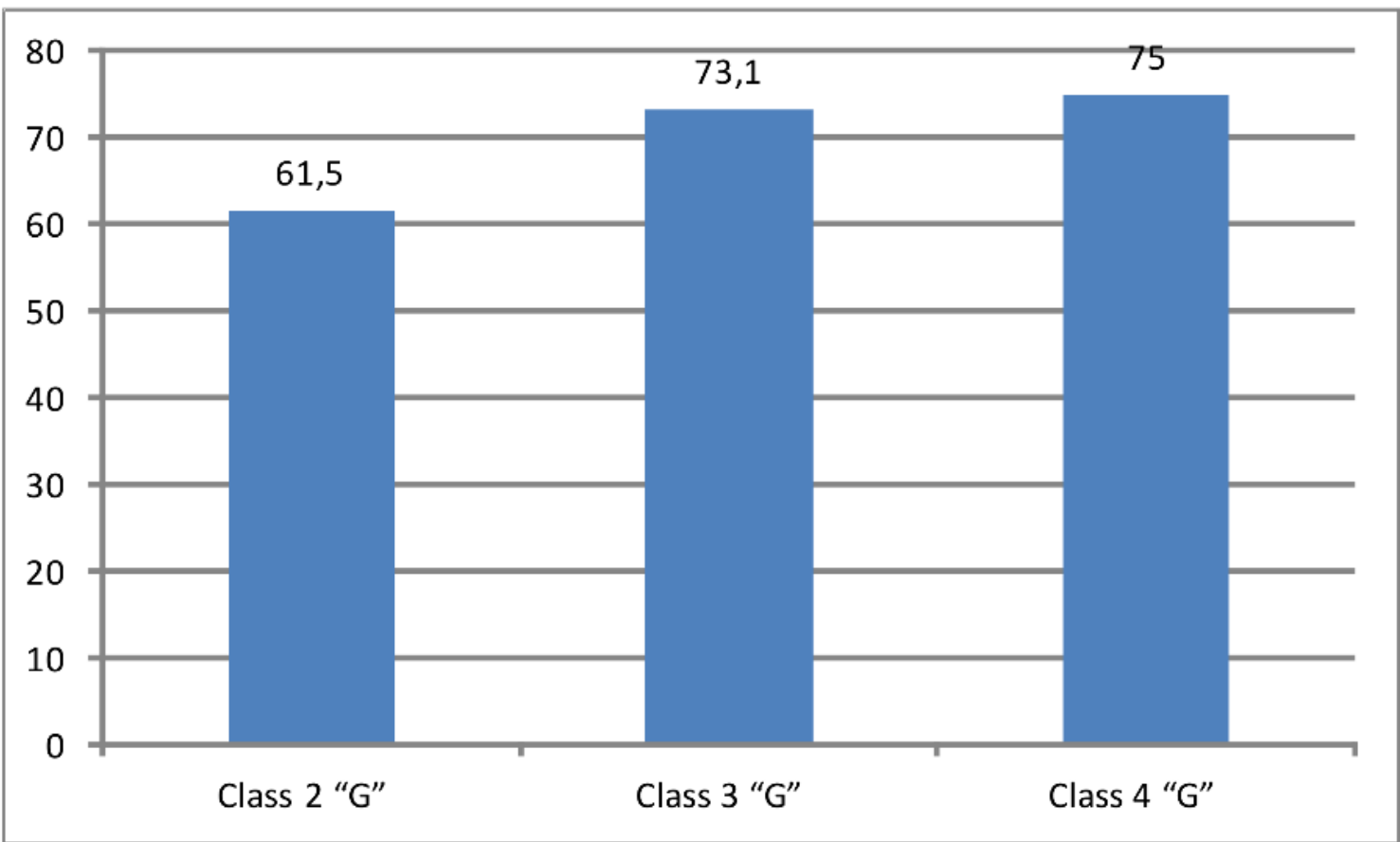

Figure 4. The level of learning process during the subject "Cognition of the world" (in \%)

Results of the introductory experiment for three years are indicators of the knowledge quality in the experimental classes. Let us consider examples of monitoring achieved by pupils results of learning for years of work of the experiment, for instance the rating evaluation system of primary school teacher F.D. Valiulina on the subject of "Cognition of the world". 
The performance results on the subject of "Cognition of the world" show the dynamics of pupils' learning growth. This is due to the features of the subject because it is more of a generic integrated nature, where primary school pupils indirectly get acquainted with the natural phenomena, the basics of Biology, Chemistry, Civics, and History of Kazakhstan. It is also necessary to take into account the seniority of the teacher - 19 years, her pedagogical activity, readiness for innovative implementations, that is reflected in the range of methods and techniques used in her work: open lessons, master classes, excursions to nature, to the library, to the plant, the use of information -communicative technologies (thematic slide presentations, training videos, online tasks, educational games, etc.). Project activity of pupils aimed at their own research has special importance in the teaching of this subject. Thus, during this period, children have developed as mini-projects, as well as a group project "Ecology of my land", as in the village of Kenkiyaktheoil fields are located. The table 2 presents fragment of result statement of learning activities of 4 " $\mathrm{G}$ " class pupils of Kenkiyak secondary school. This statement shows the transfer of a 12-point scoring system in a standard 5-point.

Assessment in the form of specific mark within the designated interval is performed by the teacher depending from admitted in the answer or written work mistakes.

The multiple types of control: a survey of homework, self-study, test task, dictation, practical work, creative work, control work, didactic game are applied in the learning process on a score system. For each type of work a pupil receives corresponding mark that by adding and dividing by the number of controls (used in one lesson) transfer into the assessment. As a result at a lesson all pupils are evaluated, no one believes himself to be free. Everyone tries to be active, initiative to score as many points to keep pace with his companions, and get a good estimate for the lesson [9].

Organization of different forms of work (individual, pair, and group) made it possible to use different methods of pupils' assessment: self-esteem, collective assessment [10].

Table 2. The fragment of learning activities among 4 "G" class pupils ofKenkiyak secondary school.

Subject: Cognition of the world, quarter 3.

\begin{tabular}{|c|c|c|c|c|c|c|c|c|c|c|c|c|}
\hline & \multicolumn{12}{|c|}{ Block №6 «Flora and Fauna of Kazakhstan" } \\
\hline & \multicolumn{6}{|c|}{ Lesson 6} & \multicolumn{6}{|c|}{ Lesson 7} \\
\hline & $\begin{array}{c}\text { Oral } \\
\text { questioning }\end{array}$ & Home task & $\begin{array}{l}\text { Complement } \\
\text { from the place }\end{array}$ & $\begin{array}{c}\text { Practical } \\
\text { work }\end{array}$ & $\begin{array}{l}\text { Total } \\
\text { points }\end{array}$ & $\begin{array}{l}\text { Assessment for the } \\
\text { lesson }\end{array}$ & Oral questioning & Home task & $\begin{array}{l}\text { Complement } \\
\text { from the place }\end{array}$ & Dictation & $\begin{array}{c}\text { Total } \\
\text { points }\end{array}$ & $\begin{array}{c}\text { Assessment for } \\
\text { the lesson }\end{array}$ \\
\hline Pupil 1 & 7 & 0 & 3 & 6 & 16 & 4 & 3 & 0 & 0 & 3 & 6 & 3 \\
\hline Pupil 2 & 0 & 5 & 0 & 5 & 10 & 4 & 0 & 3 & 3 & 3 & 9 & 4 \\
\hline Pupil 3 & 2 & 0 & 0 & 3 & 5 & 3 & 0 & 0 & 2 & 4 & 6 & 3 \\
\hline Pupil 4 & 1 & 3 & 1 & 0 & 5 & 3 & 2 & 0 & & 5 & 7 & 3 \\
\hline Pupil 5 & 6 & 8 & 0 & 10 & 4 & 5 & 4 & 9 & 3 & 11 & 27 & 5 \\
\hline Pupil 6 & 4 & 9 & 0 & 11 & 4 & 5 & 1 & 3 & 1 & 5 & 10 & 4 \\
\hline Pupil 7 & 0 & 0 & 6 & 3 & 9 & 4 & 1 & 2 & 2 & 7 & 12 & 4 \\
\hline Pupil 8 & 1 & 1 & 2 & 9 & 13 & 4 & 1 & 1 & 1 & 9 & 12 & 4 \\
\hline Pupil 9 & 5 & 0 & 5 & 0 & 10 & 4 & 3 & 0 & 3 & 3 & 9 & 4 \\
\hline Pupil 10 & 2 & 2 & 1 & 7 & 12 & 4 & 6 & 1 & 1 & 10 & 18 & 5 \\
\hline
\end{tabular}




\section{Conclusions}

Score evaluation system of pupils on Cognition the world served to the main purpose - the promotion and direction of teaching and learning activities, has accustomed pupils to self-development and self-education. The experiment helped the upbringing such important moral qualities in pupils as mutual assistance and companionship, care and respect for each other and a healthy spirit of competition. All this had a positive impact on improving the quality of pupils' knowledge and made it possible successful mastering of the program material on the subject.

According to the results of a three-year experiment on the introduction of a rating system for evaluation of pupils' achievement it can be concluded that this technology is effective, as it provides a stable positive result. It is applicable in the practice of any teacher and is particularly suitable for the study of Russian and Kazakh languages.

Rating assessment system allows to create maximal comfort environment of learning and upbringing, allows to transfer learning activities of pupils in internal need. It allows, in accordance with the individual characteristics of a pupil to make a choice between possible options and forms of mastering the discipline, allows the teacher to expand communication, to better navigate the interests and needs of pupils to know and take into account their individual characteristics. Children ceased to feel the fear the survey, loosen up, so they understood that the assessment on the subject depends on their mental abilities, psychic abilities and diligence. Activity of pupils at a lesson has increased dramatically.

\section{REFERENCES}

[1] http:/ / blog.discoveryeducation.com/ assessment/ files/ 2009/ 02/ blackbox_article.pdf

[2] Simonov V.P. Diagnostics of degree of pupil's proficiency. Educational handbook. - M.: MRA, 1999. - 48 pages

[3] Zheksenbayeva U.B. Competence orientated education at modern school: an educational and methodical book - Almaty, 2009 - 190 pages

[4] International system of estimation of knowledge/on 28 September 2011//Electronic resource. - The access Mode: http://ru.wikipedia.org/w/.

[5] Shamova, T. I. Actual problems of management of education//Management of education. - 2009. - No. 1. Page 5-8.

[6] Tomas A. Angelo, K. Patricia Kross. Technology of estimation in a class: The management for teachers of colleges. - Prod. the 2nd. - Dzhossi-Bass, 1993.

[7] AmonashviliSh.A. (1984).Educational and educative function of assessment schoolchildren's teaching. Moscow, Education, 297, 19.

[8] Zagranichnaya N.A. (2006) Estimation of the level of pupils' educational achievements of 12-year-oldschool.Astana, National Journal of 12 year education, 127, 21

[9] Zhunusova K. Birmagambetov A., Aymagambetova K., Nugumanov I., Zhukesheva K. (2004).Methodological guidance on the course "Cognition of the world" (3-4 classes) / compilers. Almaty, publishing Atamura, 217.

[10] Tsukerman G.A. (1993). Types of communication in teaching. Tomsk, publishing Peleg, 268, 173 